\title{
QUALITY AND SUSTAINABILITY OF URBAN STREET LIGHTING: A STUDY OF WARRI
}

\author{
J. 0. Asalor ${ }^{1}$ and I. W. Ujevwerume ${ }^{2, *}$ \\ 1 DEPARTMENT OF MECHANICAL ENGINEERING, UNIVERSITY OF BENIN, BENIN, Edo STATE. NIGERIA \\ 2 Department of Mechanical Engineering, Delta State Polytechnic, Otefe-Oghara, Delta State. NiGeria \\ E-mail addresses:1Joasalor1234@gmail.com,2wilfreduj@yahoo.com
}

\begin{abstract}
This paper presents the result of a study of the quality of Urban lighting. The purpose of installing the Street light is to light up all streets/roads in Warri at night. But due to some factors such as poles being brought down by accident or technical problem as a result of some bulbs that went bad without being replaced, the desired even lighting of the streets/roads was not always guaranteed. This uneven lighting which results is a hazard to road users. We modeled the evenness of light on the roads and in the process captured the uneven lighting that a road user passing the roads will experience. The results of the model and the actual measurement of the Street light that was taken for some time, showed that parts of the roads experienced full, partial, one and three quarter lightings, while some other parts were thrown in complete darkness. The implication is that users travelling along the road experienced wide variation of light that could lead to accidents. For about two and half years after the study was conducted, the authors periodically monitored the conditions of the street lights to establish the extent of their sustainability. It was noticed that all the lights went off thereby returning the streets to their pre-lighting condition. The reason for the complete disruption is also reported as a learning point in project sustainability and a learning point for the future.
\end{abstract}

Keywords: Quality, Sustainability, Road/Street light, complete lighting and half lighting.

Nomenclature

1-QL One quarter lighting

3-QL Three quarter Lighting

CD Complete darkness

CL Complete lighting

$\mathrm{d}_{\mathrm{s}} \quad$ Distance between successive poles or span length

n Number of trials

$\mathrm{N}$ Total number of poles

HL Half lighting

$\alpha \quad$ Number of poles with half lighting

$\beta \quad$ Number of poles with three quarter lighting

$\gamma \quad$ Number of poles with one quarter lighting

$\phi \quad$ Number of poles with complete lighting

$\boldsymbol{\theta}$ Number of poles with complete darkness or poles brought down by accident

\section{INTRODUCTION}

Street lightings are like other infrastructural facilities such as urban roads, water and gas supply to homes, telecommunication networks, electricity generation/ distribution with respect to how they are managed by specialists. Street light or bulb is a post generally placed at the edge or centre of a road or street or at the park or other places where there is need for public lighting. A well designed and installed street lighting system is a valuable investment because it enhances safety and security of the environment for road users at night; it can also provide social and economic benefits to the community [1]. Lighting installation must create an unbroken and uniformly clear visibility as road users move along the road and a precise perception of people and objects within the lit areas in order to minimize night-time vehicular and/or pedestrian accidents. In the presence of street lighting, accident may occur as a result of wreckleness. Studies show that night driving is more stressful to older drivers than younger ones, [2]. It is easy to infer that the presence of failed street light will produce same effect. The accident studies in Finland, [3] showed that 
darkness predisposes younger drivers to more accidents, compared to when they are driving in the day time. The outcome attributed the increase in accident partly to darkness and partly to increased blood alcohol. It was expected that the situation of driving under the conditions when street lights have failed to also predispose younger people to more accidents, it is not possible to state by how much.

The Photometric goals of Street and roadway lighting are often summarized in standards and recommended practices, among which the most common are ANSI/IES American National Standard Practice for Roadway Lighting, RP-08-00(IESNA 2000); BSI Road lighting. Performance requirements, BS EN 132012:2003 (BSI 2003); and CIE Lighting of Roads for Motor and Pedestrian Traffic, (CIE-115-2010, CIE 2010).

A system not maintained correctly will sooner or later cease to perform its required function, leading to loss of quality. Maintenance is the work undertaken in order to keep, restore or improve every facility, i.e. every part of the system, its services and surroundings to a currently acceptable standard and to sustain the utility and value of the facility, [4]. This is achieved through management planning, equipment, facilities, inventory and human resources. Various maintenance models that deal with problem of finding optimal inspection policies for systems which are subject to failures have been proposed, [5-12]. Maintaining a complex system such as street light may be difficult but it is more economical to do so than allowing the system or infrastructure to fail completely before giving attention to it. Adoption of effective preventive maintenance culture of systems can drastically reduce the cost of premature or over delayed maintenance, while accurate maintenance action can sustain continuous and reliable operation of equipment, [13].

Like other infrastructural facilities, street light works well at the beginning of installation but suffers breakdown during operation, and thus requires maintenance in order to sustain the high quality of service. A good maintenance of our infrastructural facilities will somehow sustain the quality of the desired effect of these systems which in turn can increase our economical and structural values.

In Nigeria, many cities such as Benin, Sapele, Makurdi, Effurun, Warri, Agbarho, Oghara, etc, had introduced street lighting. It is our hope that at the end of this study, end users will have good quality of lighting. We monitored and studied the street lighting system between the hours of $6 \mathrm{pm}$ and $6 \mathrm{am}$ once a week for a period of four months (January, February, March and April 2010) along Delta Steel Company (DSC) road, Okere, Odion and Cemetery roads. The street light is powered by 6 generating plants along DSC $\left(\mathrm{WS}_{1}, \mathrm{WS}_{2}\right.$ and $\mathrm{WS}_{3}$ installed 2007), Cemetery, Odion and Okere roads $\left(\mathrm{WS}_{4}, \mathrm{WS} 5\right.$ and $\mathrm{WS}_{6}$ installed 2008). This excludes the solar powered ones in the city. The problem is to establish how well the lighting is evenly distributed on the task plane. That is, to determine the quality or the uniformity of light distribution on the roads. The assumption made is that the Luminous Flux (total quantity of light emitted per second by a light source measured in lumens) from each pole on the roads is the same.

The system was modeled to reflect how the light was spread on the roads (this may not be the actual spread, but it gives a good approximation)and data were obtained for the period; areas receiving full, partial, three quarter lightings and complete darkness were evaluated. From which conclusion about the system and how it affects drivers/road users was drawn.

Following the completion of the data collection aspect of the study, the authors periodically monitored the street lighting with a view to determine their sustainability. The street light project becomes unsustainable when the project breaks down and is unable to function for a protracted period.

\section{MATERIALS AND METHODS}

There are methods proposed to measure the performance of street lighting, [14], [15], [16] and [17]; all of which deals with the measurement of luminance and illuminance. The evaluations are based on an assessment of the effectiveness of luminaire of meeting predetermined application based photometric criteria. The metric, luminaire system application efficacy (LSAE), builds upon the concept of application efficacy, which was devised to evaluate the delivery of light to where it is needed in the most energy efficient manner. Application efficacy was defined as the average luminous flux within a specific solid angle per unit power, [18]. In its calculation LSAE includes only the light output that falls on the task plane and that meets the photometric requirement of the applications task.

The quality of lighting from poles arriving at unit area on the surface of a road is shown in Figure 1. Bulbs on $\mathrm{P}_{1}$ light up distance $\mathrm{x}_{1}$ and $\mathrm{x}_{2}, \mathrm{P}_{2}$ light up distance $\mathrm{x}_{3}$ and $\mathrm{x}_{4}$, it implies that $\mathrm{P}_{\mathrm{N}}$ light up $\mathrm{x}_{2 \mathrm{~N}-1}$ and $\mathrm{x}_{2 \mathrm{~N}}$. 


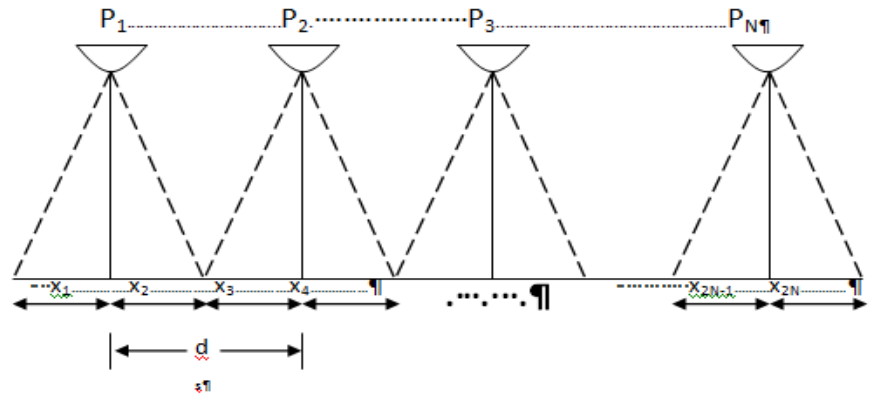

Figure 1: Portion of road fully light up

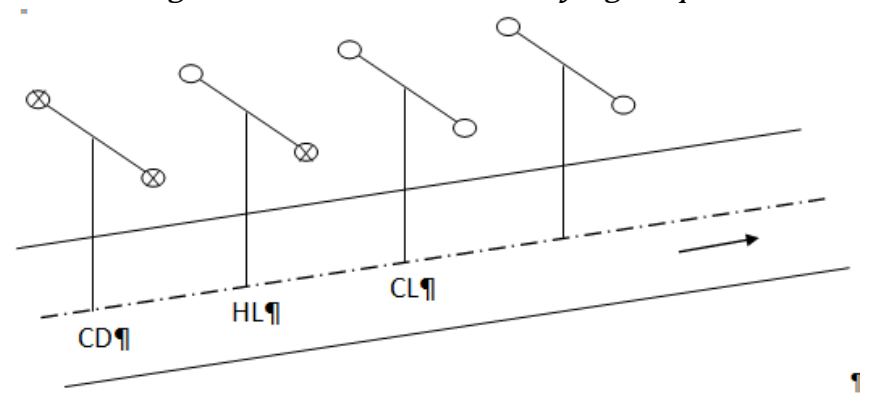

Figure 2: Quality of light distribution (double bulbs)

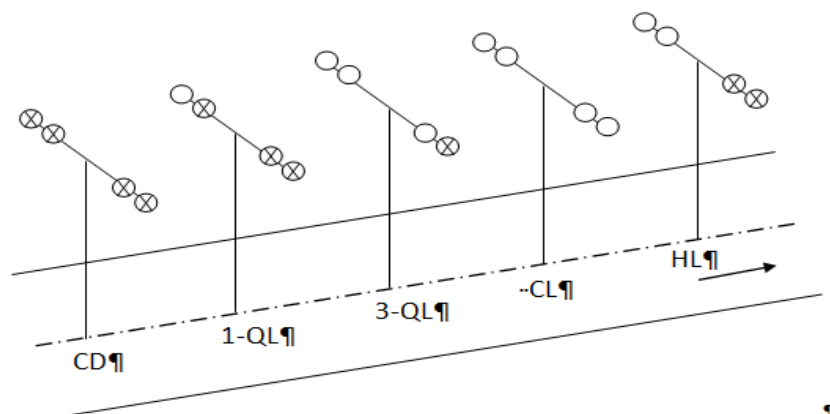

Figure 3: Quality of light distribution (quadrat bulbs)

Total distance light up,

$\mathrm{D}=\mathrm{X}_{1}+\mathrm{X}_{2} \ldots+\mathrm{X}_{2 \mathrm{~N}}=2 \mathrm{NX}_{2 \mathrm{~N}}=2 \mathrm{NX}$

Therefore,

$\mathrm{D}=\mathrm{Nd}_{\mathrm{s}}$

Some of the poles may be damaged by accident, or there could be unavailability of electricity or cable failure or some items in the fittings(bulbs, capacitors,

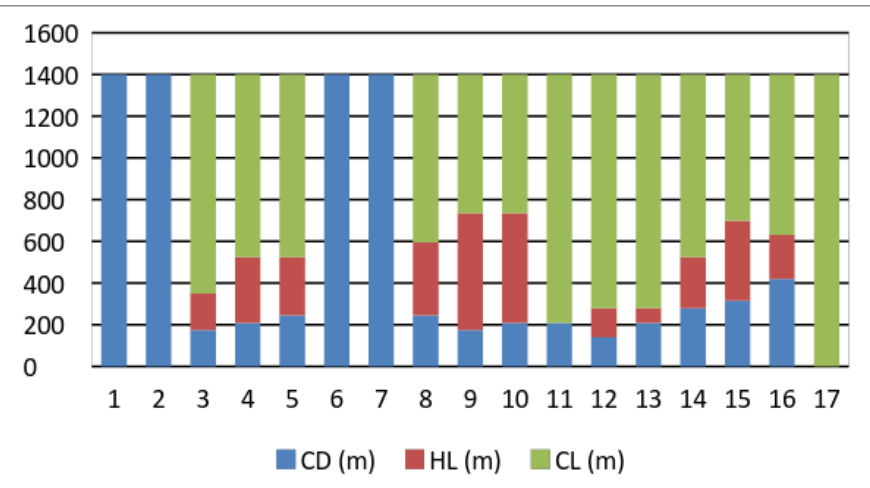

Figure 4: Proportion of Light (double bulbs) along Cemetery road igniters, chokes) could be damaged, leading to complete darkness, partial or half, three quarter, or one quarter lighting along some portions of the road as shown in Figures 2 and 3.

Luminance along the road is no longer uniform. Therefore the portion of road with:

Half lighting,

$$
\mathrm{HL}=\frac{\alpha}{\mathrm{N}} \times \mathrm{Nd}_{\mathrm{s}}=\alpha \mathrm{d}_{\mathrm{s}}
$$

Complete lighting,

$$
\mathrm{CL}=\frac{\phi}{\mathrm{N}} \times \mathrm{Nd}_{\mathrm{s}}=\alpha \mathrm{d}_{\mathrm{s}}
$$

Three quarter lighting,

$3-\mathrm{QL}=\frac{\beta}{\mathrm{N}} \times \mathrm{Nd}_{\mathrm{s}}=\beta \mathrm{d}_{\mathrm{s}}$

One quarter lighting,

$1-\mathrm{QL}=\frac{\gamma}{\mathrm{N}} \times \mathrm{Nd}_{\mathrm{s}}=\gamma \mathrm{d}_{\mathrm{s}}$

Complete darkness,

$\mathrm{CD}=\frac{\Theta}{\mathrm{N}} \times \mathrm{Nd}_{\mathrm{s}}=\theta \mathrm{d}_{\mathrm{s}}$

\subsection{Quality of Light Distribution}

A study of the system showed that some portions of roads in the town were not lit completely. As mentioned earlier, poles with double bulbs/fittings may have partial, complete lighting or complete darkness while quadrate bulbs/double fittings may have partial, complete, three quarter, one quarter or complete darkness spread along a road. Equations (2), (3) through to (6) were used, noting $d_{s}=35 \mathrm{~m}$ for road light along Cemetery, Odion and Okere roads; and $\mathrm{d}_{\mathrm{s}}$ $=50 \mathrm{~m}$ for those along DSC expressway. The results obtained are shown in figures 4-9 for each street/road The total portion of roads that received complete darkness, partial, complete, three quarter and one quarter lightings (with their proportions) for n-trials were evaluated and presented in Figures 10 and 11 for the periods.



Figure 5: Proportion of Light (quadrate bulbs) along DSC ${ }_{1}$ road 


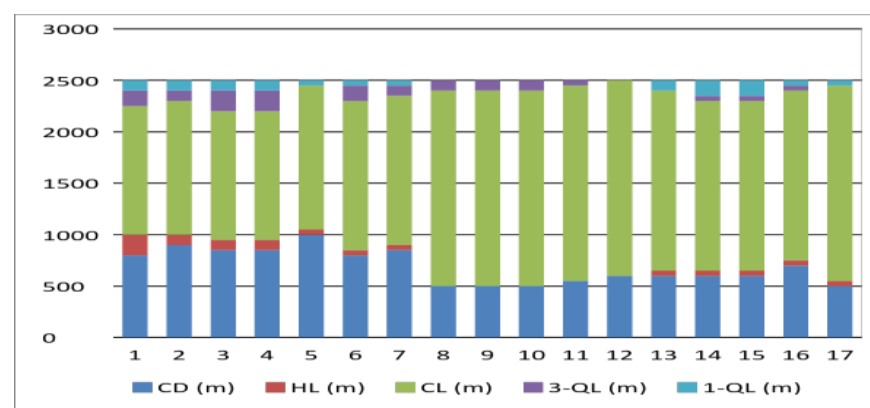

Figure 6: Proportion of Light (quadrate bulbs) along $\mathrm{DSC}_{2}$ road

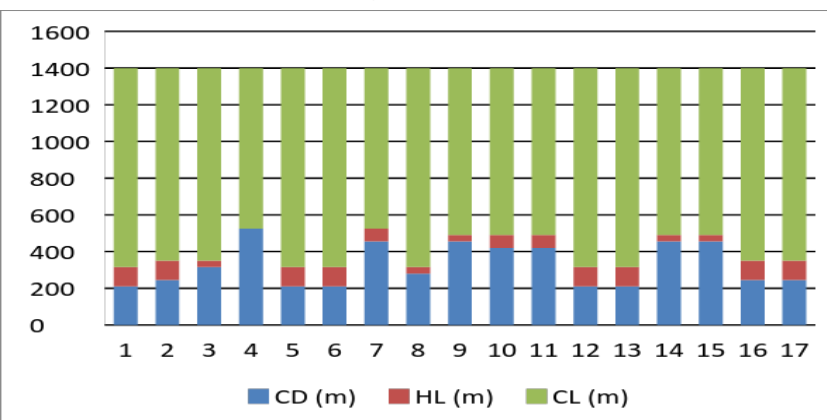

Figure 8: Proportion of Light along Odion road

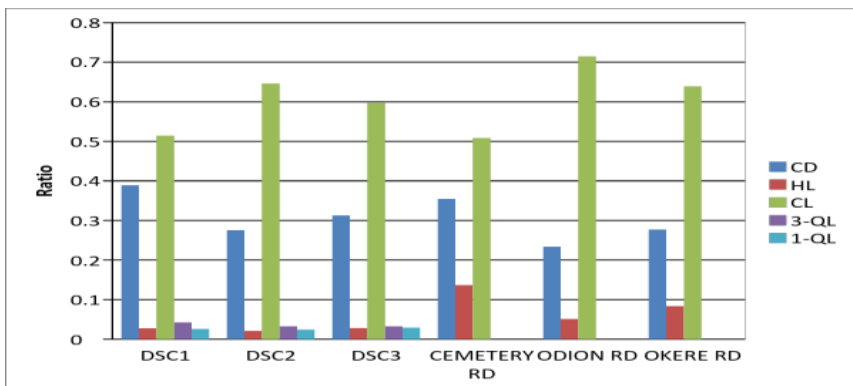

Figure 10: Overall quality of light spread (Jan-April 2010)

\section{RESULTS AND DISCUSSIONS}

Light spread along the roads is presented in Figures 4 to 9. The results show that the light was not evenly distributed. Figure 10 shows that between Jan - April 2010, users in Odion road experienced more complete lighting than users in other roads. Users in DSC1 stayed in complete darkness more than other users. While more area in Cemetery is thrown into half lighting. As at 16th February, 2012 all roads experienced less light as shown in Figure 11. Cemetery road had no light at all. Street light in Okere road has the highest performance with little or no partial failure.

For good reasons, the electricity for the street lighting was provided by a contractor using generating sets rather than the national electricity network. This is necessary because of the low availability of electricity from the national grid, varying between 0.45 and 0.75 . The operation of the generating sets require diesel which would mean the electricity generated would be more costly than that supplied from the national grid



Figure 7: Proportion of Light (quadrate bulbs) along $\mathrm{DSC}_{3}$ road

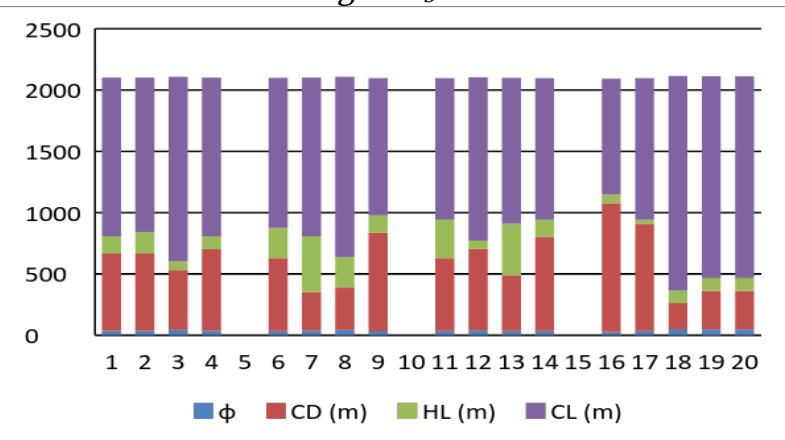

Figure 9: Proportion of Light along Okere road

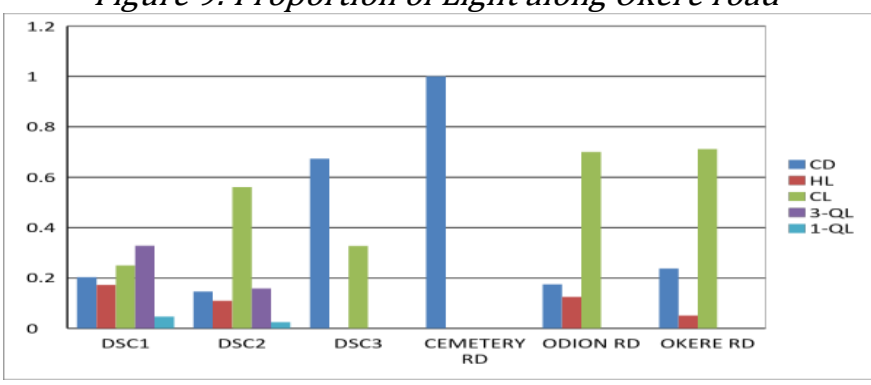

Figure 11: Overall quality of light spread (16/02/12)

with the benefit of higher availability over the operating hours of between 0.85 and 0.95 . During the 2015 general elections, the operation of the street lights became irregular and by the time the governorship elections were completed, the street lights had been shut down completely. The situation had remained so for the last four to five months. The period coincided with two events that could be responsible; first, the state government revenue declined sharply due to falling price of crude oil in the global market and second there was an intra-party change of governor in the state. Our investigation revealed that as a result of both factors, the payment to the contractor for electricity supply was stopped. Consequently, the contractor shut down generators leading to the complete breakdown of the street light scheme. The fact that the shut down of the scheme is caused partly by intra party dislocations, then there is serious cause for concern for state and national development as the disruption could be much greater when one party takes over from another as frequently 
happens in the states in Nigeria. In World Bank discussion papers several similar disruptions due to actors commitment to development project were identified and they include the type that has caused the shutdown of the street light under study [19]

\section{CONCLUSION}

The effectiveness of street lights in Warri has been determined for the period between January and April 2010. All parts of the roads were not uniformly lit, thereby, exposing users travelling along the road, to experience wide variation of lighting.

The results show that in $\mathrm{DSC}_{1}$ road, about $51 \%$ of the road had full lighting; $\mathrm{DSC}_{2}$ about $65 \%$ of the road had full lighting; $\mathrm{DSC}_{3} 60 \%$ of the road had full lighting; in Odion road, $71 \%$ of the road had full lighting; in Okere road, $64 \%$ of the road had full lighting; and in Cemetery road $51 \%$ of the road had full lighting. Thus, Odion road experienced the best lighting followed by $\mathrm{DSC}_{2}$ road.

The study has been able to indicate the varying intensity of the street lights as would be experienced by travelers along the road with the potential to cause disorientation.

The study has also revealed two sources of unsustainability of a useful public infrastructure/ utility namely economic downturn and state - level intra party political changes. A result of the consequences of these changes is the complete shutdown of the scheme at a great loss to the served public.

\section{REFERENCES}

[1] Rea, M. S. Illuminating Engineering Society of North America, Lighting Handbook, Reference and Application, Editor, New York, 2000.

[2] Liisa, H. Older Drivers in Finland, Traffic Safety and Behaviour, The central Organisation for Traffic Safety, Liikenneturva, 1994.

[3] Liisa, H. Compensation in Older Drivers as Reflected in their Fatal Accidents, The central Organisation for Traffic Safety, Liikenneturva, 1993.

[4] Agunwambaa, J. C., Tarzomonb, T.T \& Nwojic, C.U. "Application of Christer's Inspection Model for Building Maintenance", Nigerian Journal of Technology, Vol. 31, Number 2, July, 2012, pp. 98106.

[5] Pierskalla. W. P. and Voelker, J. A. "A Survey of Maintenance Models: The Control and Surveillance of Deteriorating Systems", Naval Research Logistics Quarterly, Vol. 23, 1976, pp. 353-388.

[6] Sherif. Y. S. and Smith, M. L. "Optimal Maintenance Models for Systems Subject to Failure - A Review", Naval Research Logistics Quarterly, Vol. 28, 1981, pp. 47-74.

[7] Christer, A. H. "Modelling Inspection Policies for Building Maintenance", Journal of the Operational Research Society, Vol. 33, 1982, pp. 723-732.

[8] Thomas, L. C. "A survey of Maintenance and Replacement Models for Maintainability of Multiitem Systems" Reliability Engineering, Vol. 16, 1986, pp. 297-309.

[9] Valdez-Flores, C. and Feldman, M. A. "Survey of Preventive Maintenance Models for Stochastically Deteriorating Single-unit Systems", Naval Research Logistics Quarterly, Vol. 36, 1989, pp. 419-446.

[10] Clio. D. I. and Parlar, M. A. "Survey of Maintenance Models for Multi-unit Systems", European Journal of Operational Research, Vol. 5 1, 1991, pp. 1-23.

[11] Thomas. L. C., Gaver, D. P. and Jacobs, P. A. "Inspection Models and their Application", IMA Journal of Mathematics Applied in Business and Industry, Vol. 3, 1991, pp. 283-303.

[12] White, D. J. "A Survey of Applications of Markov Decision Processes", Journal of the Operational Research Society, Volume 44, 1993, pp. 1073-1096.

[13] Ozor, P. A. \& Onyegegbu, S. O. "Design of Preventive Maintenance Scheduling Model for Deteriorating Systems" , Nigerian Journal of Technology, vol. 3, Number 3, 2011, p. 1.

[14] BSI. Code of Practice for the Design of road Lighting, Parts 1 \& 2, BS 5489, British Standards Institution, London, 2003.

[15] BSI. Road Lighting. Parts 2, 3, 4, BS EN 13201, British Standards Institution, London, 2003.

[16] Alliance for Solid-State Illumination Systems and Technologies, "ASSIST recommends ... Recommendations for Evaluating Street and Roadway Luminaires", Troy, New York. Lighting Research Centre, Vol. 10, Issue 1, 2011, pp. 5-11.

[17] Alliance for Solid-State Illumination Systems and Technologies (ASSIST). "ASSIST recommends... Recommendations for Evaluating Parking Lot Luminaires", Troy, New York. Lighting Research Centre, Vol. 7, Issue 3, 2010.

[18] Rea, M. S. \& Bullough, J.D. "Application efficacy", Journal of the Illuminating Engineering Society, Vol. 30, Number 2, 2001: pp. 73-96.

[19] Heaver R. \& Israel A. "Country Commitment to Development Projects", The World Bank Washington, D. C. U. S. A. 1986. 